\title{
PENICILLIN: ITS DEVELOPMENT FOR MEDICAL USES*
}

\author{
BY PROF. H. W. FLOREY, F.R.S.
}

University of Oxford

$\mathrm{P}$ ENICILLIN has received a great deal of publicity in the lay Press during the last year or two, largely, I suspect, because of the somewhat unusual and dramatic circumstances of its discovery and development. Though some of the accounts are substantially correct, others, both British and American, have not been so reliable.

It has been known since Pasteur described the phenomenon in 1877 that in a test tube in the laboratory, the growth of one species of bacterium may be stopped by the concomitant growth of another. It is now known that this is due to the production by the antagonistic micro-organism of a definite chemical product. To these naturally produced chemical inhibitors, the name of 'antibiotic' has recently been given. Pasteur recognized that the phenomenon of antibiosis might be of use in therapeutics, but the first serious attempt to use it was made by Emmerich and Loew in 1899, when they suggested that the products of a common microorganism, B. pyocyaneus, could be used for treating anthrax and diphtheria. It is certainly true that this bacillus produces more than one antibiotic, but the mixture called 'pyocyanase' has never really been shown to be of use in medicine.

In the course of years, many examples of the production of antibiotics were found; in fact in 1929 a monograph was published about them, but none had at that time been employed successfully in medicine.

\section{Discovery of Penicillin}

In 1929, Prof. A. Fleming, of St. Mary's Hospital, London, made a very acute observation. He was examining the growth and properties of Staphylococcus. This organism grows readily on a solid medium containing agar. In the course of his observations, Fleming had to lift the lid on and off in order to examine the staphylococci growing in the dish. Now everywhere in the air around us are bacteria and spores of moulds. If the lid of an agar plate is left off for only a fow minutes, bacteria and spores settle on the agar and in a few days the surface is covered with a thick growth of bacteria and moulds. During Fleming's short manipulations, a mould spore settled on his agar plate, which was then put aside for a few days. Such a contamination is extremely common, but what was remarkable in this instance was fortunately noticed by Fleming, who had for many years been interested in antiseptics. Around the mould colony, the colonies of staphylococci were undergoing lysis, that is, dissolving.

Fleming took some of the mould and cultivated it in flasks, in liquid broth. He found that during its growth something appeared in the broth which was capable of inhibiting the growth of a number of microbes, including many of those which cause some of the most destructive lesions the flesh is heir to. This substance Fleming called 'penicillin'. The mould was afterwards identified as Penicillium * Substance of a Friday discourse delivered at the Royal Institution
on December 10 . notatum. It is not a common mould, and is not the kind found on bread, old boots and such-like.

Fleming found that penicillin-containing broth was not more poisonous to animals than ordinary broth, and that the broth did not appear to harm white blood cells. He recognized that penicillin might be of value in medicine as an antiseptic to apply to infected wounds, and after treating a few indolenseptic wounds with the broth, he concluded that, as he said, "it certainly appeared to be superior to dressings containing potent chemicals".

Clutterbuck, Lovell and Raistrick found in 1932 that the mould could be grown on a purely synthetic liquid medium, but they did not succeed in extracting the penicillin from the liquid in stable form. They found, however, that if the medium was acidified and shaken with ether, the penicillin passed into the ether. Unfortunately, when they tried to get rid of the ether and concentrate the penicillin by evapora. tion, most of the penicillin activity was lost.

\section{Discovery of the Chemotherapeutic Effects of Penicillin}

Fleming, and also Clutterbuck, Lovell and Raistrick, concluded that penicillin is a very unstable substance and therefore not likely to be a practicable antiseptic, and the matter rested there until the work was taken up at the School of Pathology, Oxford, in 1939. Since 1929, I had been interested in another discovery of Fleming's-lysozymo-a substance occurring in many animal tissues and secretions which has the power of dissolving certain air bacteria, though unfortunately none which produces disease. The work on lysozyme was continued on the biochemical side during the 1930's, until it was purified by Roberts in 1937, and the material or substrate on which it acted characterized by Epstein and Chain in 1940. During the latter part of this work in 1938, Dr. Chain and I decided that it would be profitable to make a systematic survey of naturally produced antibacterial substances both from a biochemical and biological aspect. The first two to be investigated were the products of $B$. pyocyaneus, the bacterium to which I have already referred, and penicillin. Penicillin was chosen (in spite of the fact that it was said to be very unstable) because it acted against disease-producing bacteria, in particular the staphylococcus. One observation of Fleming and of Clutterbuck, Lovell and Raistrick suggested that penicillin was not too unstable to handle; that was, that its activity might, under certain conditions, be maintained in the original medium for some weeks. At the beginning of the work we thought that penicillin would be an enzyme or ferment like lysozyme, and we were certainly unprepared to discover its remarkable properties which came to light in the course of the investigations. The work which we now began needed the close collaboration of many workers. In addition to Dr. E. Chain, these colleagues have been Dr. E. P. Abraham, Prof. A. D. Gardner, Dr. N. G. Heatley, Dr. M. A. Jennings, Dr. A. G. Sanders, Dr. C. M. Fletcher and Mrs. Florey, with the collab. 
oration of many surgeons and physicians ; I should like to emphasize that without their unstinted efforts the work would never have been carried through to its present stage. Nor must one forget how much was due to our technical assistants, Mr. G. Glister and his 'penicillin girls', Mr. J. Kent and, for the chemical work, Mr. D. Callow.

One of the first steps was the elaboration by Heatley of a quick test for penicillin, which made the quick assay of penicillin-containing fluids possible.

At first the mould was grown in flasks ; later, when more material was required, it was grown in larger vessels.

Preliminary experiments showed that penicillin was an acid which in the acid form rapidly lost its activity. It was also destroyed by alkali but was stable at a point which was neither acid nor alkaline, that is, about neutrality. Further, Clutterbuck, Lovell and Raistrick's observation was confirmed that, if penicillin-containing brew was made acid and shaken with ether, the penicillin passed into the ether. The crucial observation was then made that when the ether containing penicillin was shaken with water containing the right amount of alkali, the penicillin passed from the ether back into water. In this way the penicillin could be extracted from the crude brew and partially purified. The processes now used for the preparation of penicillin all depend, at one stage or another, on transference of penicillin from a water solution to an organic solvent and back.

It must be realized that in the early days we had very little penicillin for the experimental work on which some of the essential chemical data were obtained. The main factors affecting the use of penicillin in medicine are that salts of penicillin: (1) are stable about neutrality ; (2) they are destroyed by acid and alkalis; (3) by oxidizing agents such as potassium permanganate; (4) by certain metals such as copper, lead and mercury; (5) by some alcohols; and (6) by enzymes or ferments produced by certain air bacteria.

One of the most important points is its destruction by an enzyme or ferment produced by certain air bacteria. These bacteria are ubiquitous and very easily contaminate the fluids in which penicillin is grown. If this occurs, the enzyme produced by the bacteria destroy the penicillin as fast as the mould produces it. It is, in fact, the air bacteria which make large-scale production of penicillin so difficult, for it is by no means easy to carry out manipulations on a large scale while excluding these organisms.

The isolation from the original medium of a protein- and salt-free product made possible a study of the bacteriological and pharmacological properties in detail.

Some of the bacteria highly susceptible to penicillin are Streptococcus pyogenes (causing pus formation and.such diseases as child-bed fever), Staphylococcus aureus (causing bone diseases and boils, etc.), both of which are important in war wounds, Streptococcus pneumonioe (causing pneumonia), Corynebacterium diphtherice (causing diphtheria), Clostridium welchii, septique and oedematiens (causing gas gangrene), Neisseria gonorrhoce (causing gonorrhœa), Neisseria meningitidis (causing meningitis or spotted fever).

Some much less sensitive are those causing typhoid fever and a form of food poisoning, while some, such as those causing plague, cholera, dysentery and tuberculosis, are quite insensitive. It is thus clear that penicillin is not a cure-all, and it cannot be expected to act except in diseases caused by susceptible organisms.

Most antiseptics, like carbolic acid, kill the germs outright; but penicillin merely stops their growth, that is, it is what is called a bacteriostatic. It interferes in some way not yet clear with bacterial division.

Some of the first material produced inhibited the growth of an organism such as the streptococcus at a dilution of $1: 1,000,000$. We made the erroneous deduction that anything so powerful as this must be fairly pure, but we now know that only about 1 to 2 per cent of the original brown powder was pure penicillin. What is now commonly called penicillin for use in medicine still contains not more than 10-20 per cent of the active material, the rest being coloured and other impurities.

\section{Pharmacological Properties}

While this chemical and bacteriological work was proceeding, investigations were also made on its pharmacological properties. The most important points are: (1) lack of toxicity to mice and other animals ; (2) white blood cells (leucocytes) and tissue cultures (body cells grown in glass vessels) are unaffected by concentrations of penicillin some hundred of times greater than that necessary to stop bacterial growth; (3) the activity of penicillin is not affected by pus, blood or the breakdown products of dead tissues; (4) its activity is little affected by the number of bacteria present; (5) it is absorbed after injection into muscle or beneath the skin and from the small intestine; (6) it cannot be given by stomach owing to the presence of acid there, nor by the large bowel owing to the presence of bacteria which destroy it; (7) it is very rapidly excreted by the urine, hence large and frequent doses have to be given. It is also excreted in the bile.

Points 3 and 4 are in sharp contrast to the sulphonamides.

It is most important that penicillin has little effect on the white blood cells or leucocytes, for it is to these that we owe a great deal of the capacity of the body to combat infection. If germs gain entrance, say, through a prick in the finger, the blood vessels dilate and certain of the white blood cells emig ate from the blood vessels to the tissues. They move freely about in the tissues, where they take up and kill bacteria if they meet them. But the bacteria produce poisons which kill the white blood cells, and the outcome of the infection is to a large extent controlled by which factor is the greater-the killing of the leucocytes by the bacteria or vice versa.

It will now be appreciated how penicillin acts in combating bacteria which have gained entry to the body. It stops the growth of the germs, while the white blood cells ingest them and kill them off.

The final experiments which demonstrated that penicillin might be useful in medicine were those known as mouse protection experiments. A number of mice are inoculated with germs which will certainly kill them if no successful treatment is given. We sat up through the night injecting penicillin every three hours into the treated group, and I must confess that it was one of the more exciting moments when we found in the morning that all the untreated mice were dead and all the penicillin-treated ones alive. The diseases treated experimentally were 
caused by the streptococcus, the staphylococcus and a gas gangrene organism. Against the latter two organisms there is no other really effective drug.

A man is roughly 3,000 times the weight of a mouse, so you can well imagine that the next step, to produce enough to use on man, took months of labour on the scale at which we were then working. Fventually enough was made to give a single small injection to a man. Much to our consternation, the patient started shivering and the temperature rose. Fortunately, the substance causing this reaction was not penicillin, and the impurity was removed quite easily by chemical means.

Work in the laboratory having provided all the necessary knowledge to enable us to say penicillin could be used on man, and what sort of infections it was likely to deal with, the object of the first trials on man was to see if the drug exhibited any toxicity not found in animals and to ascertain the best methods of administration and the necessary dosage.

Penicillin can be used in two ways; it can be injected intravenously or intramuscularly, after which it is carried by the blood stream to the diseased parts. By this means much penicillin has to be used, but it is the only possible way of giving it in many serious illnesses. It may also be used in much less quantities as a local application to infected parts. Its successful use locally clearly depends on being able to reach every part of the diseased area, and one of the main points in its use is the elaboration of the requisite surgical techniques to ensure this.

There is no question that this drug can perform in a remarkable way when rightly used but, as with all new drugs, the initial trials tend to be carried out on what are considered hopeless cases after everything else has been tried. Though it is recognized now that penicillin is a valuable drug, it is still so rare that patients are not treated until the disease has progressed a long way and everything else has been tried. What one looks forward to is its use at the earliest possible moment with the idea of stopping or preventing destruction of the tissues, and so saving much disability and prolonged illness, and even life. It is probably along these lines of prevention, for example, that it will be most profitable to use the material for those wounded in battle.

At the present time there are dozens of chemists both in Great Britain and in the United States, in academic laboratories and commercial firms, engaged on the chemical problems, and we must await the result of their labours with what patience we can. In the meantime, great efforts are being made to improve the yields produced by the mould by means of selecting a good specimen or strain of the mould, and by improving the media. A considerable measure of success has been achieved, particularly by our American colleagues. Just as the Americans have had our information we have theirs, and commercial firms both in Great Britain and America are now doing all they can to make this drug available in quantity in the shortest possible time.

I venture to suggest that in another five or ten years the work I have been describing will be looked on as the first halting steps in the exploration of a whole series of new chemotherapeutic compounds, and I think the discovery and development of penicillin may be looked on as quite one of the luckiest accidents that have occurred in medicine, for without exception all other mould antibiotics so far examined are poisonous.
INFLUENCE OF NEWTON'S WORK ON SCIENTIFIC THOUGHT*

\author{
By N. TEICH, \\ University of Leeds
}

$\mathrm{B}^{\mathrm{x}}$ $Y$ his extraordinary talent Newton was able not only to produce a powerful synthesis of the work done by his immediate predecessors, Galileo and Kepler, but also to add profound contributions of his own to mechanics, mathematics and optics. His method of fluxions enabled him to produce quantitative calculations which raised the level of mechanical science to hitherto unknown heights. The mechanical interpretation of Nature to which he gave such a powerful stimulus became one of the leading factors in the subsequent development of scientific thought.

The question arises now whether it is possible in discussing the scientific side of Newton's influence to omit his influence on the philosophical and social side? Evolution of scientific thought does not depend only on experiments and calculations. It is true that scientific men are in the first place responsible for scientific thought. But they do not live in a vacuum. They are social beings; they take part consciously or unconsciously in the life of society surrounding them. Social ideas which agitate society also affect their ideas.

What was the social background to which we have to look in order to understand the essential levers of Newton's work? Whoever takes a plunge into the history of Newton's period cannot help observing that the intellectual activities of Newton and his contemporaries went side by side with the struggle for political rights between the old nobility and the rising class of merchants. All activities in military and commercial spheres needed the active help of people well versed in the theoretical principles of astronomy (for navigation) and of mechanics (for building simple machines or using cannons). It is not surprising, therefore, that the physical theory of that time occupied itself mainly with the motions of stars or of bodies encountered in everyday experience. People needed scientific knowledge in order to improve their living. What Francis Bacon hoped for when he said that "the roads of human power and human knowledge lie close together" became a reality more than ever before at the time of Newton in England, and at the end of the eighteenth century in France. It is no accident that the essentially materialistic conception of mechanical science scored such a profound victory first in England, then in France, because in these countries the social changes which we associate with the bourgeois revolutions of 1642 and 1789 were favourable to a materialistic philo. sophy.

Although the immediate social impacts gave rise to the comprehensive theory and practice of mechanics as worked out by Newton, we must not forget the historical continuity which binds the Newtonian outlook to the earlier English materialists, Roger Bacon and Francis Bacon, and to the schoolmen Duns Scotus and William of Occam. English materialistic thought culminated in Newton's work in mechanical science despite the theological limitation Newton imposed on himself.

The brilliant success of Newton's work as applied

* Essay awarded the Foyle Prize of the University of Leeds. 